\title{
Human Factors and Ergonomics in Health Care and Patient Safety from the Perspective of Medical Residents
}

\author{
Pascale Carayon, Peter Kleinschmidt, \\ Bat-Zion Hose, and Megan Salwei
}

\subsection{Introduction}

Health care is about people with various roles (e.g., patient, caregiver, clinician) who interact and collaborate in connected care processes of diagnosis, treatment, monitoring, and management. Ensuring that these processes produce "good" outcomes for patients (e.g., quality of care, patient safety, positive patient experience) as well as for clinicians involved in their care (e.g., quality of working life of clinicians) remains a major challenge around the world. The US National Academies' report on Crossing the Global Quality Chasm [1] indicates that inappropriate and unsafe care remain widespread around the world. In particular, "between 5.7 and 8.4 million deaths occur annually from poor quality of care in LMICs for ... selected set of conditions ..., which represents between $10 \%$ and $15 \%$ of the total deaths in LMICs ... in 2015" (page S-2).

P. Carayon $(\bowtie)$

Department of Industrial and Systems Engineering,

Wisconsin Institute of Healthcare Systems

Engineering, University of Wisconsin-Madison,

Madison, WI, USA

e-mail: pcarayon@wisc.edu

P. Kleinschmidt

UW Health, Madison, WI, USA

e-mail: PKleinschmidt@uwhealth.org

B.-Z. Hose · M. Salwei

University of Wisconsin-Madison,

Madison, WI, USA

e-mail: bhose@wisc.edu; msalwei@wisc.edu
Two other reports also published in 2018 draw attention to patient safety challenges and gaps in health care quality around the world [2]. Systems approaches have been recommended to address these complex health care quality and patient safety problems [1, 3], as well as to improve work systems and working conditions for clinicians [4].

The discipline of human factors (or ergonomics) (HFE) provides systems concepts and methods to improve care processes and outcomes for patients, caregivers, and clinicians. According to the International Ergonomics Association, HFE is "the scientific discipline concerned with the understanding of interactions among humans and other elements of a system, and the profession that applies theory, principles, data and methods to design in order to optimize human well-being and overall system performance" [5]. According to this definition of HFE by the IEA, people are at the center of (work) systems; systems and their elements and interactions should be designed to support performance and enhance well-being of people. HFE emphasizes the physical, cognitive, and organizational dimensions of work systems. Medical residents are key stakeholders in delivery of high-quality, safe care; they are often at the center of work systems that deliver care to patients in hospitals, primary care or specialty care facilities, emergency departments, and other care settings. Therefore, it is important to design the work system of medical residents to improve 
quality and safety of care. The discipline, approaches, and methods of HFE can help to achieve this goal.

\subsection{Application of SEIPS Model to Medical Residents}

The SEIPS (Systems Engineering Initiative for Patient Safety) model [6, 7] is an HFE systems model that can be used to describe the work of medical residents and its impact on patient safety and resident outcomes, such as well-being, safety, and learning. According to the SEIPS model, medical residents perform a range of tasks (e.g., clinical tasks, learning activities) using various tools and technologies; this occurs in a physical and organizational environment (see Fig. 7.1). The design of the work system, i.e., its individual elements and their interactions, influences care processes and educational processes, which in turn produce outcomes for patients (e.g., patient safety) and for residents (e.g., well-being, learning).

Medical residents perform a range of tasks that have been documented and described in multiple studies. For instance, Carayon et al. [8] described the work of residents in intensive care units (ICUs), including adult, pediatric, medical, and surgical units. Prior to conducting observations, researchers developed a list of 17 tasks (e.g., direct patient interaction). Four human factors engineers observed residents in multiple ICUs for a total of $242 \mathrm{~h}$. Observers recorded time spent by residents in the following categories: (1) direct patient care (e.g., clinical review and documentation), (2) care coordination (e.g., conversation with team physician), (3) indirect patient care (e.g., administrative review and documentation), and (4) non-patient care (e.g., nonclinical conversation). Other studies of medical residents have also shown that significant proportion of their time is spent on tasks that are indirectly related to patient care [9] and that medical residents are often interrupted while performing tasks [10].

Residents perform tasks using various technologies, in particular health information technologies such as EHR (electronic health record) and CPOE (computerized provider order entry). Those technologies have significant impact on tasks performed by residents, including time spent on various tasks and the sequence or flow

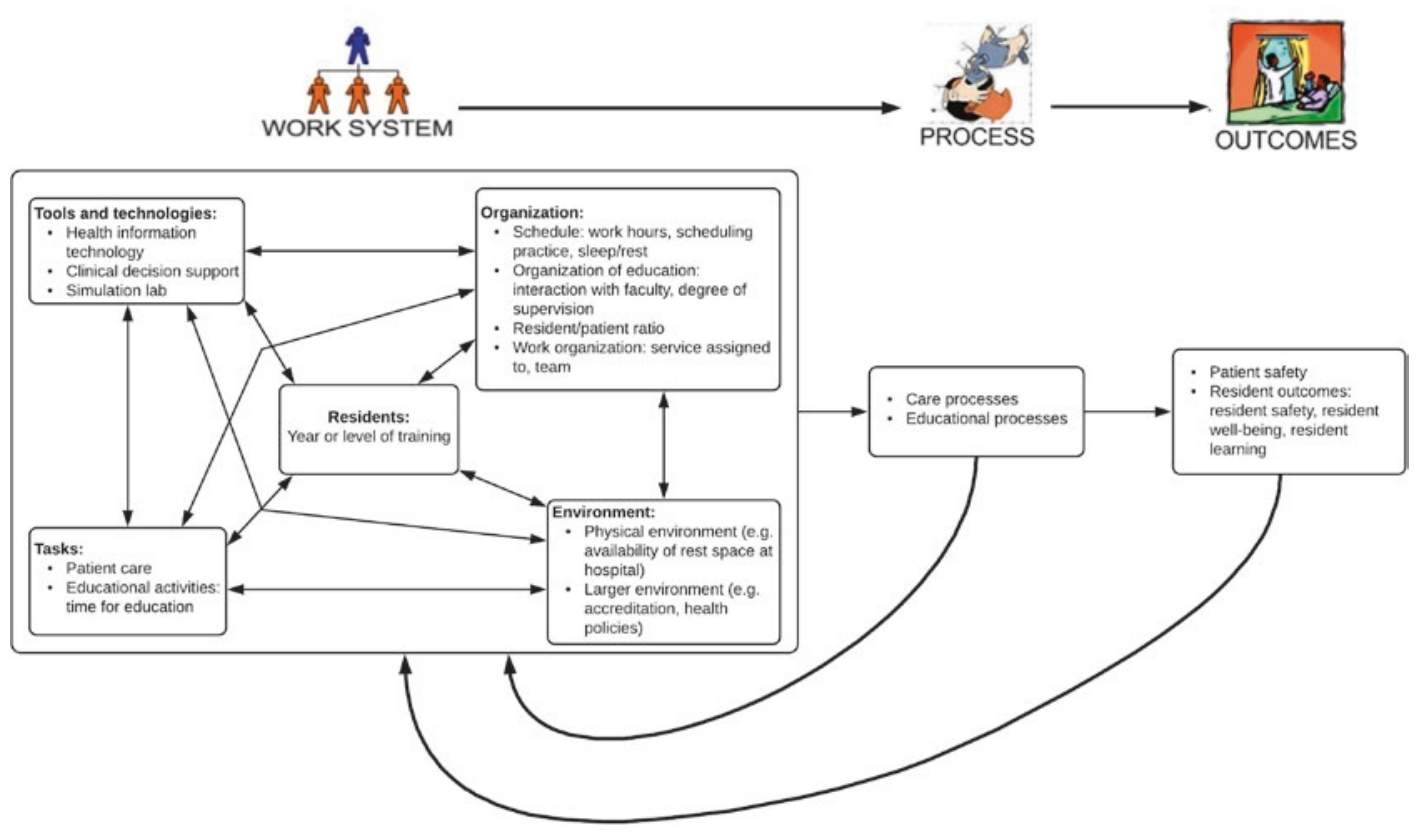

Fig. 7.1 SEIPS model applied to medical residents 
of tasks. For instance, after the implementation of EHR technology in intensive care units, residents spent significantly more time on clinical documentation and review: from $18 \%$ to $31 \%$, respectively, before and after EHR implementation [11]. They also performed a higher frequency of activities per hour after EHR implementation: from 117 to 154 activities per hour. This may reflect increased intensification of work around the use of EHR technology.

Eden et al. [12] described several work system factors in graduate medical education that interact and influence residents' educational process and resident learning; these work system interactions impact the extent to which the resident workforce is able to provide high-quality, patientcentered, and affordable health care. For instance, the payment structures (organization), availability of accredited residency positions (environment), as well as lifestyle and demographic factors (person) affect the residency pipeline and the number of physicians in specialty and subspecialty fields. Other work system factors, such as telehealth (technology) and an increased presence of physician assistants (organization) are changing the roles, responsibilities, and work demands of physicians. The graduate medical education work system should be designed so that the educational processes produce physicians that can support the health needs and goals of populations around the world.

A recent report by the National Academies of Sciences, Engineering, and Medicine demonstrates the influence of work system factors on resident well-being. Forty-five to sixty percent of medical residents' experience symptoms of burnout, which is characterized by high emotional exhaustion, high depersonalization, and a low sense of accomplishment from work [13]. In particular, the electronic health record (technology) is recognized as a source of burnout among physicians. For instance, in a study of residents and teaching physicians, $37 \%$ reported at least 1 symptom of burnout with $75 \%$ associating burnout with the use of the EHR. Additionally, physicians who used the EHR after work for more than $6 \mathrm{~h}$ per week were 3 times more likely to report symptoms of burnout compared to physicians who spent $6 \mathrm{~h}$ or less per week [14]. The negative impact of the EHR on resident well-being is in part due to the increased clerical (tasks) and documentation (organization) burden. The SEIPS model can be used to understand how work system factors interact and influence resident outcomes such as burnout and learning).

We adapted a scenario from the AHRQ (Agency for Healthcare Research and Quality) WebM\&M website (https://psnet.ahrq.gov/) to demonstrate how work system elements can interact and influence patient care.

\begin{abstract}
A 70-year-old healthy man (person) went to a routine follow-up appointment (task) with his primary care doctor (person). His doctor (person) was a third-year internal medicine resident in his final month of training and would soon leave the institution to begin his fellowship. After a discussion with the patient, the resident decided to screen him for prostate cancer with the prostate-specific antigen (PSA) test (person and task). In the past, the patient's PSA tests had always been normal. This time, the patient's PSA test returned and was elevated at a level where cancer is almost certain (83 ng/ml). However, the resident had completed his training before receiving an electronic alert (technology) about the patient's PSA test. The electronic alert remained unread (technology, task, organization) as there was no system in place that supported smooth handoffs to oncoming residents (organization, task, person). Several months later, the patient (person) presented with low back pain. His new physician, another internal medicine resident (person), ordered imaging tests (task) that confirmed metastatic prostate cancer. While the new resident (person) reviewed the patient's chart (task and technology), he uncovered the missed follow-up for the patient's elevated PSA.
\end{abstract}

This scenario includes several interacting work system elements (e.g., technology and organization) that resulted in a patient's delayed diagnosis of prostate cancer.

\subsection{Linkage of Work System to Patient Safety and Medical Resident Well-Being}

One of the primary drivers of workplace reform as it relates to resident well-being and health is through the institution of duty hour limitations. 
This reform is largely attributed to the death of Libby Zion, an 18-year-old woman who was under the care of residents in a hospital emergency department in New York City in 1984 [15]. Publicity from this case spurred conversations about fatigue and patient safety issues connected to unrestricted hours worked by residents, and many countries began to impose work hour limitations in the 1990s as a result. The European Working Time Directive became law in 1998 and included limiting physicians working hours to $48 \mathrm{~h}$ per week and limiting hours for physicians in training [16]. Training hours in the United States limited work hours first in 2003 [17], then further in 2011 to a cap of $80 \mathrm{~h}$ per week, with the aim of improving both patient safety and trainee safety [18].

Measuring the impact of duty hour restrictions has been controversial. A systematic review in 2015 on work hour restrictions found inconsistent results, often with studies in direct contradiction with expectations regarding patient safety and resident well-being [19]. Since then two large randomized controlled trials have evaluated outcomes more extensively, randomizing trainees to restrictive conditions under the 2011 limits vs more flexible schedules. The FIRST trial randomized 118 surgical programs and first published results in 2015. This was followed by the iCOMPARE trial, which randomized 63 internal medicine residency programs. In both studies, primary outcomes included no difference in patient safety events between groups $[20,21]$ and no significant difference in educational outcomes between groups [22]. Residents in the iCOMPARE trial were more satisfied with their educational experience in the work hour restricted arm of the study though this effect was not seen in the FIRST trial, while program directors were more satisfied in the flexible schedule study arm.

The exact degree of duty hour restriction necessary to impact patient safety remains controversial [23]. Critics of studies showing minimal impact argue that work hour restrictions are inconsistently applied or may not be carefully implemented [24]. For example, limiting time at work on duty may just shift to more work at home when off duty, or compressing work to a nar- rower window and leading to increased stress [25]. Despite results of the FIRST and iCOMPARE trials, significant data exist to show that extended shifts in the hospital setting can have adverse effects on technical and cognitive performance and lead to impairment outside the workplace [26-28].

Work hour limitations in the EU are generally more restrictive than in the United States yet have led to similarly controversial results. A systematic review by Rodriguez-Jareño and colleagues [23] found that long working hours, defined by the European Working Time Directive as more than $48 \mathrm{~h}$ per week, to be associated with an increased incidence of physician needle-stick injuries and motor vehicle accidents. Additionally, a study by Zahrai et al. [29] found a significant relationship between resident hours spent in the hospital and poor general health and physical function. However, another study found no improvements in resident self-reported physical health by reducing working hours [30].

Despite these controversies, efforts should be made to mitigate fatigue and burnout. Burnout has been demonstrated to increase cognitive failures and difficulties with attention [31]. A systematic review demonstrated a strong connection between poor well-being and negative patient safety outcomes such as medical errors. This was particularly closely linked with depression, anxiety, poor quality of life, and stress, along with moderate to high levels of burnout [32]. Growing data on the impact of burnout on both clinical outcomes and physician safety has led to repeated calls for greater emphasis on addressing this issue [33]. This is critical as it relates to training environments for residents along with the broader systems in which health care professionals work; it is becoming more apparent that fatigue and burnout is a significant safety issue for both patients and physicians, including physicians-intraining. Outside of duty hours, several other work system factors can contribute to poor resident well-being, fatigue, and burnout including training, work schedule flexibility, autonomy, clinical experience, and supervisor behavior [34, 35]. As there are multiple, sometimes conflicting goals, regulations on working hours as well as 
other work system factors (e.g., flexibility of schedules, technology design, training environment) should be carefully considered in order to mitigate negative effects on residents and patient safety.

\subsection{Challenges and Trade-Offs in Improving Residents' Work System}

Medical residents work and learn in various care settings and in interaction with other clinicians. The challenge is how to optimize the work system of medical residents, as well as the work systems of others that are involved in patient care. In a previous section, we discussed the challenge of designing safe and healthy work schedules for medical residents. Some interventions aimed at reducing work hours of medical residents have unfortunately had negative impact on the attending physicians who supervise them: work gets passed on from medical residents to attending physicians who are then experiencing overload and stress. Therefore, any intervention aimed at improving the work system of medical residents needs to prevent or mitigate negative consequences for other health care professionals involved in patient care.

Improving residents' work system can be challenging as it may lead to improvement in some outcomes, but deterioration in other outcomes. Myers et al. [36] assessed internal medicine and general surgical residents' attitudes about the effects of the Accreditation Council for General Medical Education duty hours regulations effective July 1, 2003 [37]. They surveyed 111 internal medicine residents and 48 general surgical residents from six geographically diverse programs in the United States. The sample was limited to residents who had experienced residency before and after implementation of the duty hours regulations. The survey included questions on residents' opinions of [1] quality of patient care and safety and [2] residency education. Both medical and surgical residents reported that the quality of care decreased with continuity of care decreasing a lot. Medical resi- dents reported a greater decrease in available opportunities for bedside learning and teaching than surgical residents. The authors of the study noted that duty hours reform may lead to teaching hospitals caring for the same patient volume with fewer resident physician-hours; therefore, intensifying the work of residents. Thus, there is a need to optimize and improve the resident work system to consider all outcomes, including continuity of patient care and educational opportunities.

\subsection{Role of Residents in Improving Their Work System}

There is a long tradition in the HFE literature and practice of involving "workers" in work system redesign; this is known as participatory ergonomics [38]. In participatory ergonomics projects, the "workers" participate in providing input and ideas about how to improve tasks, technologies, environments, organizations, and processes. Sometimes workers are actively engaged in making decisions about how to redesign the work system. Participatory ergonomics projects vary with regard to content (e.g., improving the design of EHR technology), decision making (e.g., providing input or making decisions on process improvement), and stage (e.g., initial analysis of work system or implementation of redesign) [39]. In a project aimed at enhancing family engagement in bedside rounding in a pediatric hospital, researchers implemented a participatory ergonomics process in which residents along with attending physicians, nurses, and parent proposed and helped to implement a bundle of interventions [40]. The interventions consisted of a checklist of best practices for engaging families during bedside rounding (e.g., introducing health care team members) and training of residents in the new rounding process. Specific elements of the checklist (e.g., asking the family for questions, reading back orders) were related to improvement in perceived quality and safety of care by parents [41]. Involving residents in this work system and process redesign was critical to 
the successful implementation of the interventions as key stakeholders. In addition to involving residents in specific improvement projects, health care organizations have created dedicated structures to involve residents more systematically, such as involvement of residents in safety/quality councils [42].

The Institute of Medicine report "Resident Duty Hours: Enhancing Sleep, Supervision, and Safety" [43] spurred a significant change in resident work structure. It also prompted greater emphasis on both training and direct resident involvement in quality improvement and patient safety initiatives. Out of this movement, the Accreditation Council for Graduate Medical Education in the United States (ACGME) drafted its Clinical Learning Environment Review (CLER) guidelines in 2014 [44]. Included in the guidelines are requirements that training programs integrate quality improvement and patient safety training into resident curricula and that residents should have direct involvement in organizational quality improvement projects. Hospitals and health systems have taken a variety of strategies to fulfill this requirement while also integrating residents into quality improvement initiatives and work system redesigns.

A systematic review in 2010 identified components for a resident quality curriculum, which should include concepts of continuous quality improvement, root cause analysis, and systems thinking [45]. Implementation of quality curricula was well accepted and effective in improving knowledge. Further, $32 \%$ of studied curricula (13/41) resulted in local changes in care delivery and $17 \%$ (13/41) significantly improved target processes of care, indicating that direct training itself of trainees can improve the quality environment of an organization.

Several organizations have heeded the call for resident involvement in improving their work systems by establishing quality councils and safety officer positions for residents and other trainees [4]. This is a critical component to boosting resident involvement in safety and quality improvement their institutions. In the following paragraph, we lay out a model for a resident safety council drawing on experiences published by several institutions in the United States and Canada [42, 46]. Similar councils have since demonstrated measurable improvements in improvements in patient safety goals $[47,48]$.

The following should be considered when designing and implementing a resident safety council:

- The council should be resident led.

- Appoint a resident chair who works directly along system administrators and other hospital groups to direct quality improvement projects.

- Relevant subcommittees, for example, Quality, Safety, Research, Education, each chaired by council members can further direct the focus of the group.

- Agendas and meeting topics are both chosen by and presented by residents to this helps assure that meetings remain interactive and productive, rather than becoming a series of lectures.

- The safety council should remain voluntary though with an effort to establish representation from all training programs at an institution.

- Encourage a multidisciplinary presence at council meetings. Graduate medical education staff, hospital administrators, representatives from organizational QI and patient safety departments, and patient-family representatives should all be involved in meetings.

- The safety council should serve as a tool to draw residents directly onto institutional QI committees, such as Event Evaluation Teams, Root Cause Analysis, Medical Records committees, and Interdisciplinary Model of Care Committees.

Implementing a robust quality improvement and safety curriculum supported by a resident-led council can empower residents to implement large-scale quality work, to engage their peers, and help foster growth of the next generation of leaders in patient safety. 


\subsection{Conclusion}

In many health care organizations, especially academic medical centers, residents are the primary clinicians providing patient care. Recognizing the unique needs of medical residents both in their role of delivering safe and effective care and also in meeting their educational objectives requires a robust approach to understand the work systems in which residents operate. Human factors and ergonomics principles, and specifically the Systems Engineering Initiative for Patient Safety (SEIPS) model, can inform decisions when working to evaluate and improve resident work systems. This is particularly important when addressing patient safety and resident well-being. As health care becomes increasingly interconnected and reliant on multidisciplinary teams, it is important to consider unanticipated consequences of changes in work systems, particularly on how they may affect processes and outcomes for residents, but also for all other team members.

Acknowledgments This chapter was supported by the Clinical and Translational Science Award (CTSA) program, through the NIH National Center for Advancing Translational Sciences (NCATS), Grant Number: 1UL1TR002373. The content is solely the responsibility of the authors and does not necessarily represent the official views of the NIH.

\section{References}

1. NASEM (National Academies of Sciences E, and Medicine). Crossing the global quality chasm. Washington, DC: The National Academies Press; 2018.

2. Berwick DM, Kelley E, Kruk ME, Nishtar S, Pate MA. Three global health-care quality reports in 2018 . Lancet. 2018;392(10143):194-5.

3. Kaplan GS, Bo-Linn G, Carayon P, Pronovost P, Rouse W, Reid P, et al. Bringing a systems approach to health. Washington, DC: Institute of Medicine and National Academy of Engineering; 2013.

4. NASEM (National Academies of Sciences E, and Medicine). Taking action against clinician burnout: a systems approach to professional well-being. Washington, DC: National Academies Press; 2019.

5. International Ergonomics Association (IEA). The discipline of ergonomics. 2000. http://www.iea.cc/ ergonomics/.
6. Carayon P, Hundt AS, Karsh B-T, Gurses AP, Alvarado CJ, Smith M, et al. Work system design for patient safety: the SEIPS model. Qual Saf Health Care. 2006;15(Suppl I):i50-8.

7. Carayon P, Wetterneck TB, Rivera-Rodriguez AJ, Hundt AS, Hoonakker P, Holden R, et al. Human factors systems approach to healthcare quality and patient safety. Appl Ergon. 2014;45(1):14-25.

8. Carayon $\mathrm{P}$, Weinger MB, Brown R, Cartmill R, Slagle J, Van Roy KS, et al. How do residents spend their time in the intensive care unit? Am J Med Sci. 2015;350(5):403-8.

9. Hollingsworth JC, Chisholm CD, Giles BK, Cordell WH, Nelson DR. How do physicians and nurses spend their time in the emergency department? Ann Emerg Med. 1998;31(1):87-91.

10. Gabow PAMD, Karkhanis AMS, Knight ARN, Dixon PP, Eisert SP, Albert RKMD. Observations of residents' work activities for 24 consecutive hours: Implications for workflow redesign. Acad Med. 2006;81(8):766-75.

11. Carayon P, Wetterneck TB, Alyousef B, Brown RL, Cartmill RS, McGuire K, et al. Impact of electronic health record technology on the work and workflow of physicians in the intensive care unit. Int J Med Inf. 2015;84(8):578-94.

12. Eden J, Berwick D, Wilensky G. Graduate medical education that meets the nation's health needs. ERIC; 2014.

13. National Academies of Sciences E, and Medicine. Taking action against clinician burnout: a systems approach to professional well-being. Washington, DC: National Academies Press; 2020.

14. Robertson SL, Robinson MD, Reid A. Electronic health record effects on work-life balance and burnout within the I(3) population collaborative. J Grad Med Educ. 2017;9(4):479-84.

15. Brensilver JM, Smith L, Lyttle CS. Impact of the Libby Zion case on graduate medical education in internal medicine. Mt Sinai J Med (NY). 1998;65(4):296-300.

16. BMA-What is the European Working Time Directive? 31 Dec 2019. Available from: https://www. bma.org.uk/advice/employment/working-hours/ewtd.

17. Ulmer C. Committee on Optimizing Graduate Medical Trainee (Resident) Hours and Work Schedules to Improve Patient Safety for the Institute of Medicine. Resident duty hours: enhancing sleep, supervision, and safety. 2008.

18. Nasca TJ, Day SH, Amis ES Jr. The new recommendations on duty hours from the ACGME Task Force. N Engl J Med. 2010;363:e3(1)-e3(6).

19. Bolster L, Rourke L. The effect of restricting residents' duty hours on patient safety, resident well-being, and resident education: an updated systematic review. J Grad Med Educ. 2015;7(3):349-63.

20. Bilimoria KY, Chung JW, Hedges LV, Dahlke AR, Love R, Cohen ME, et al. National cluster-randomized trial of duty-hour flexibility in surgical training. N Engl J Med. 2016;374(8):713-27. 
21. Silber JH, Bellini LM, Shea JA, Desai SV, Dinges DF, Basner M, et al. Patient safety outcomes under flexible and standard resident duty-hour rules. N Engl J Med. 2019;380(10):905-14.

22. Desai SV, Asch DA, Bellini LM, Chaiyachati KH, Liu M, Sternberg AL, et al. Education outcomes in a duty-hour flexibility trial in internal medicine. N Engl J Med. 2018;378(16):1494-508.

23. Rodriguez-Jareño MC, Demou E, Vargas-Prada S, Sanati KA, Škerjanc A, Reis PG, et al. European Working Time Directive and doctors' health: a systematic review of the available epidemiological evidence. BMJ Open. 2014;4(7):e004916.

24. McMahon GT. Managing the most precious resource in medicine. N Engl J Med. 2018;378(16):1552-4.

25. Auger KA, Landrigan CP, Gonzalez del Rey JA, Sieplinga KR, Sucharew HJ, Simmons JM. Better rested, but more stressed? Evidence of the effects of resident work hour restrictions. Acad Pediatr. 2012;12(4):335-43.

26. Barger LK, Cade BE, Ayas NT, Cronin JW, Rosner B, Speizer FE, et al. Extended work shifts and the risk of motor vehicle crashes among interns. N Engl J Med. 2005;352(2):125-34.

27. Ayas NT, Barger LK, Cade BE, Hashimoto DM, Rosner B, Cronin JW, et al. Extended work duration and the risk of self-reported percutaneous injuries in interns. JAMA. 2006;296(9):1055-62.

28. Ware JC, Risser MR, Manser T, Karlson JKH. Medical resident driving simulator performance following a night on call. Behav Sleep Med. 2006;4(1):1-12.

29. Zahrai A, Chahal J, Stojimirovic D, Schemitsch EH, Yee A, Kraemer W. Quality of life and educational benefit among orthopedic surgery residents: a prospective, multicentre comparison of the night float and the standard call systems. Can J Surg. 2011;54(1):25.

30. Stamp T, Termuhlen P, Miller S, Nolan D, Hutzel P, Gilchrist $\mathrm{J}$, et al. Before and after resident work hour limitations: an objective assessment of the well-being of surgical residents. Curr Surg. 2005;62(1):117-21.

31. Linden DVD, Keijsers GPJ, Eling P, Schaijk RV. Work stress and attentional difficulties: an initial study on burnout and cognitive failures. Work Stress. 2005;19(1):23-36.

32. Hall LH, Johnson J, Watt I, Tsipa A, O'Connor DB. Healthcare staff wellbeing, burnout, and patient safety: a systematic review. PLoS One. 2016;11(7):e0159015.

33. Dyrbye LN, Shanafelt TD, Sinsky CA, Cipriano PF, Bhatt J, Ommaya A, et al. Burnout among health care professionals: a call to explore and address this underrecognized threat to safe, high-quality care. Washington, DC: National Academy of Medicine; 2017.

34. Dyrbye L, Shanafelt T. A narrative review on burnout experienced by medical students and residents. Med Educ. 2016;50(1):132-49.
35. Eckleberry-Hunt J, Lick D, Boura J, Hunt R, Balasubramaniam M, Mulhem E, et al. An exploratory study of resident burnout and wellness. Acad Med. 2009;84(2):269-77.

36. Myers JS, Bellini LM, Morris JB, Graham D, Katz J, Potts JR, et al. Internal medicine and general surgery residents' attitudes about the ACGME duty hours regulations: a multicenter study. Acad Med. 2006;81(12):1052-8.

37. Philibert I, Friedmann P, Williams WT, Hours ftmotAWGoRD. New requirements for resident duty hours. JAMA. 2002;288(9):1112-4.

38. Noro K, Imada A. Participatory ergonomics. London: Taylor \& Francis; 1991.

39. Haines H, Wilson JR, Vink P, Koningsveld E. Validating a framework for participatory ergonomics (the PEF). Ergonomics. 2002;45(4):309-27.

40. Xie A, Carayon P, Cox ED, Cartmill R, Li Y, Wetterneck TB, et al. Application of participatory ergonomics to the redesign of the family-centred rounds process. Ergonomics. 2015;58:1726-44.

41. Cox ED, Jacobson GC, Rajamanickam VP, Carayon P, Kelly MM, Wetterneck TB, et al. A familycentered rounds checklist, family engagement, and patient safety: a randomized trial. Pediatrics. 2017;139(5):e1688.

42. Tevis SE, Ravi S, Buel L, Clough B, Goelzer S. Blueprint for a successful resident quality and safety council. J Grad Med Educ. 2016;8(3):328-31.

43. Ulmer C, Wolman DW, Johns ME, editors. Resident duty hours: enhancing sleep, supervision, and safety. Washington, DC: The National Academies Press; 2008.

44. Weiss KB, Bagian JP, Wagner R. CLER pathways to excellence: expectations for an optimal clinical learning environment (executive summary). J Grad Med Educ. 2014;6(3):610-1.

45. Wong BM, Etchells EE, Kuper A, Levinson W, Shojania KG. Teaching quality improvement and patient safety to trainees: a systematic review. Acad Med. 2010;85(9):1425-39.

46. Liao JM, Co JP, Kachalia A. Providing educational content and context for training the next generation of physicians in quality improvement. Acad Med. 2015;90(9):1241-5.

47. Dueker JM, Luty J, Perry DA, Izumi S, Fromme EK, DiVeronica M. A resident-led initiative to increase documentation of surrogate decision makers for hospitalized patients. J Grad Med Educ. 2019;11(3):295-300.

48. Cohen SP, Pelletier JH, Ladd JM, Feeney C, Parente V, Shaikh SK. Success of a resident-led safety council: a model for satisfying CLER pathways to excellence patient Safety goals. J Grad Med Educ. 2019;11(2):226-30. 
Open Access This chapter is licensed under the terms of the Creative Commons Attribution 4.0 International License (http://creativecommons.org/licenses/by/4.0/), which permits use, sharing, adaptation, distribution and reproduction in any medium or format, as long as you give appropriate credit to the original author(s) and the source, provide a link to the Creative Commons license and indicate if changes were made.

The images or other third party material in this chapter are included in the chapter's Creative Commons license, unless indicated otherwise in a credit line to the material. If material is not included in the chapter's Creative Commons license and your intended use is not permitted by statutory regulation or exceeds the permitted use, you will need to obtain permission directly from the copyright holder. 